Article

\title{
The Effect of Sulfuric Acid Concentration on the Physical and Electrochemical Properties of Vanadyl Solutions
}

\author{
Jamie S. Lawton ${ }^{1}$, Sophia M. Tiano ${ }^{2}$, Daniel J. Donnelly ${ }^{2}$, Sean P. Flanagan ${ }^{2}$ and \\ Thomas M. Arruda 2,* (D) \\ 1 Department of Chemistry and Biochemistry, University of Massachusetts Dartmouth, \\ N. Dartmouth, MA 02747, USA; jlawton2@umassd.edu \\ 2 Department of Chemistry, Salve Regina University, Newport, RI 02840, USA; \\ sophia.tiano@salve.edu (S.M.T.); daniel.donnelly@salve.edu (D.J.D.); sean.flanagan@salve.edu (S.P.F.) \\ * Correspondence: thomas.arruda@salve.edu; Tel.: +1-401-341-2467
}

Received: 30 May 2018; Accepted: 23 July 2018; Published: 1 September 2018

\begin{abstract}
The effects of sulfuric acid concentration in $\mathrm{VO}^{2+}$ solutions were investigated via electrochemical methods and electron paramagnetic resonance. The viscosity of solutions containing $0.01 \mathrm{M} \mathrm{VOSO}_{4}$ in 0.1-7.0 $\mathrm{M} \mathrm{H}_{2} \mathrm{SO}_{4}$ was measured. Diffusion coefficients were independently measured via electrochemical methods and electron paramagnetic resonance (EPR), with excellent agreement between the techniques employed and literature values. Analysis of cyclic voltammograms suggest the oxidation of $\mathrm{VO}^{2+}$ to $\mathrm{VO}_{2}{ }^{+}$is quasi-reversible at high $\mathrm{H}_{2} \mathrm{SO}_{4}$ concentrations $(>5 \mathrm{~mol} / \mathrm{L}$ ), and approaching irreversible at lower $\mathrm{H}_{2} \mathrm{SO}_{4}$ concentrations. Further analysis reveals a likely electrochemical/chemical (EC) mechanism where the $\mathrm{H}_{2} \mathrm{SO}_{4}$ facilitates the electrochemical step but hinders the chemical step. Fundamental insights of $\mathrm{VO}^{2+} / \mathrm{H}_{2} \mathrm{SO}_{4}$ solutions can lead to a more comprehensive understanding of the concentration effects in electrolyte solutions.
\end{abstract}

Keywords: vanadium redox flow batteries (VRFBs); cyclic voltammetry; electrochemical kinetics; viscosity; electron paramagnetic resonance; diffusion coefficient

\section{Introduction}

Flow batteries, including the all-vanadium redox flow battery (VRFB), have recently received considerable attention as a possible solution to large grid energy storage needs [1]. Numerous experimental [2] and modeling studies [3] have been conducted to understand and improve flow battery technology. A detailed understanding of the electrolyte dynamics and how they change with parameters like temperature and concentration is an important fundamental step in flow battery research [4-6]. For instance, many modeling studies rely on physical parameters, such as viscosity, diffusion coefficient, permeability, mobility, activation energy, and others. However, these values are often not known for the specific conditions at which models are evaluated; thus, modelers often rely on the available parameters of nearest relevance, potentially leading to incorrect models.

The vanadium electrolyte in VRFBs frequently begins as a solution of vanadyl sulfate and sulfuric acid, which is charged to the necessary oxidation states to form the anolyte and catholyte solutions for the uncharged battery [7]. Concentrations ranging from $0.1-2 \mathrm{M} \mathrm{VOSO}_{4}$ and 1-5 M $\mathrm{H}_{2} \mathrm{SO}_{4}$ have been reported in characterization studies [6]. Significant interest has been given to the diffusion and uptake of vanadium in the ion exchange membranes that separate the negative and positive electrodes. Vanadium crossover through the membrane leads to self-discharge of the battery. The composition of the electrolyte has been shown to play an important role in this process [8-11]. Vanadium crossover could potentially lead to concentration mismatches, which, in severe cases 
could require complete electrolyte remixing which could result in downtime. Thus, a complete understanding of these dynamics will assist in further development of VRFBs and enhance their performance and marketability.

Some limitations of current battery technology include the kinetics of the reactions and the solubility of the reactants at varying temperatures and $\mathrm{pH}$ values. A number of organic additives, including L-Glutamic acid [12] and inositol and phytic acid [13], have been investigated to improve the energy density of the battery. A variety of sulfates and phosphates have also been investigated to inhibit vanadium precipitation [14]. A foundation of fundamental information to understand the effects of sulfate, acid, and other components of the electrolyte systems can aide in the pursuit of improved electrolytes for battery operation by using a knowledge-based approach.

Diffusion coefficients for translational diffusion can be measured in a variety of ways. Electrochemically, it is possible to measure the diffusion coefficient with cyclic voltammetry using the Randles-Sevcik equation, through chronoamperometry using the Cottrell equation, and through rotating disc electrode methods (cyclic or linear sweep voltammetry) using the Koutecky-Levich equation. Furthermore, these methods can provide complementary information, as long as they are carefully executed under the conditions for which the equations have been developed. In many cases, the validity of these equations depends on boundary conditions that are not relevant to actual battery operation. For instance, activities are often replaced by concentrations for convenience, as the assumption is acceptable for dilute solutions. However, as concentrations increase appreciably (i.e., values relevant to VRFBs) so does the deviation from activity, thus rendering the equations inaccurate. For this reason, we employ ideal-dilute battery electrolytes for this initial study. It is worth noting that as $\mathrm{H}_{2} \mathrm{SO}_{4}$ concentrations increase, so does viscosity which will cause a decrease in diffusion coefficients. This is also the case for $\mathrm{VOSO}_{4}$ concentrations $[4,15]$ but the focus of this paper is on the effect of the acid concentration on the system, so low concentrations of $\mathrm{VOSO}_{4}$ minimize the effect of the later, which will be addressed in future studies.

Rotational diffusion can be determined using electron paramagnetic resonance (EPR). EPR is a technique that can be used to observe species with unpaired electrons, which the V(IV) in $\mathrm{VO}^{2+}$ has. EPR is sensitive to the motions of detectible species, which makes it a useful tool for energy research where species mobility is important [16-20]. Rotational diffusion and translational diffusion can be related via the Stokes-Einstein and the Stokes-Einstein-Debye equations. In this approach, the translational diffusion can be determined separately by different methods and compared to ensure accuracy.

The concept of electrochemical reversibility/irreversibility, which is kinetically driven, is another important consideration, and should not be confused with chemical reversibility/irreversibility, which is thermodynamically driven. Electrochemical reversibility can be measured using cyclic voltammetry by inspecting the difference in peak potentials, $\Delta E_{p}$, which is related to the reaction rate $k_{0}[21,22]$. This is a powerful electroanalytical method applicable to any redox process, including VRFB reactions. Previous investigations [23] have indicated that $\mathrm{VO}^{2+}$ oxidation exhibits higher reversibility with increasing $\mathrm{H}_{2} \mathrm{SO}_{4}$ concentration, though the voltammograms are highly asymmetric at $2 \mathrm{M}$ $\mathrm{VO}^{2+}$. Here, we fully investigate the reversibility of $\mathrm{VO}^{2+}$ oxidation and interpret the data to make conclusions about the effects of $\mathrm{H}_{2} \mathrm{SO}_{4}$ on the electrochemical rate.

In order to more fully understand the dynamics in these electrolyte solutions, we begin with a study looking at the effects of $\mathrm{H}_{2} \mathrm{SO}_{4}$ concentration on the diffusion, hydrodynamic or Stokes radius and oxidation of the vanadyl $\left(\mathrm{VO}^{2+}\right)$ ion in dilute solutions of $\mathrm{VOSO}_{4}$. The effects of $\mathrm{H}_{2} \mathrm{SO}_{4}$ on these physical and electrochemical properties can be used to guide further electrolyte and battery developments and provide insight into the kinetics of $\mathrm{VO}^{2+}$ oxidation. In addition to gaining understanding of the effects of $\mathrm{H}_{2} \mathrm{SO}_{4}$ concentration, these physical characteristics, we develop some insight into the electrochemical redox mechanism for the oxidation of $\mathrm{VO}^{2+}$ and subsequent reduction of $\mathrm{VO}_{2}{ }^{+}$, which cannot be achieved by standard VRFB cycling studies. It is worth noting that these 
fundamental studies have been carried out on smooth, polished glassy carbon electrodes. The kinetics of $\mathrm{VO}^{2+} / \mathrm{VO}_{2}{ }^{+}$are sensitive to the electrode surface structure and area as described previously $[24,25]$.

\section{Results and Discussion}

The influence of $0.01 \mathrm{MVOSO}_{4}$ has a negligible effect on the viscosity of the $\mathrm{H}_{2} \mathrm{SO}_{4}$ electrolyte. Figure 1 plots the Arrhenius-type plots for viscous flow for solutions with and without $\mathrm{VO}^{2+}$ :

$$
\eta=\eta_{\infty} e^{\frac{E a}{R T}}
$$

where $E_{a}$ is the activation energy for viscous flow, $\eta_{\infty}$ is the viscosity at infinite temperature, $R$ is the gas constant, and $T$ is temperature. The viscosity data and extracted Arrhenius parameters are made available in Tables A2 and A3 in Appendix A, respectively. As with the viscosity, the presence of this low concentration of $\mathrm{VO}^{2+}$ has little to no effect on the activation energy $\left(E_{a}\right)$ or the intercept $\left(\eta_{\infty}\right)$. The systematic increase in solution viscosity with $\mathrm{H}_{2} \mathrm{SO}_{4}$ concentration is expected, as pure $\mathrm{H}_{2} \mathrm{SO}_{4}$ has a high viscosity $\left(\sim 26 \mathrm{cP}\right.$ at $\left.20^{\circ} \mathrm{C}\right)$; thus, the viscosity is expected to generally increase with the increasing mole fraction of $\mathrm{H}_{2} \mathrm{SO}_{4}$. These viscosity data were collected and used in the analyses of the electrochemistry and EPR experiments discussed below.

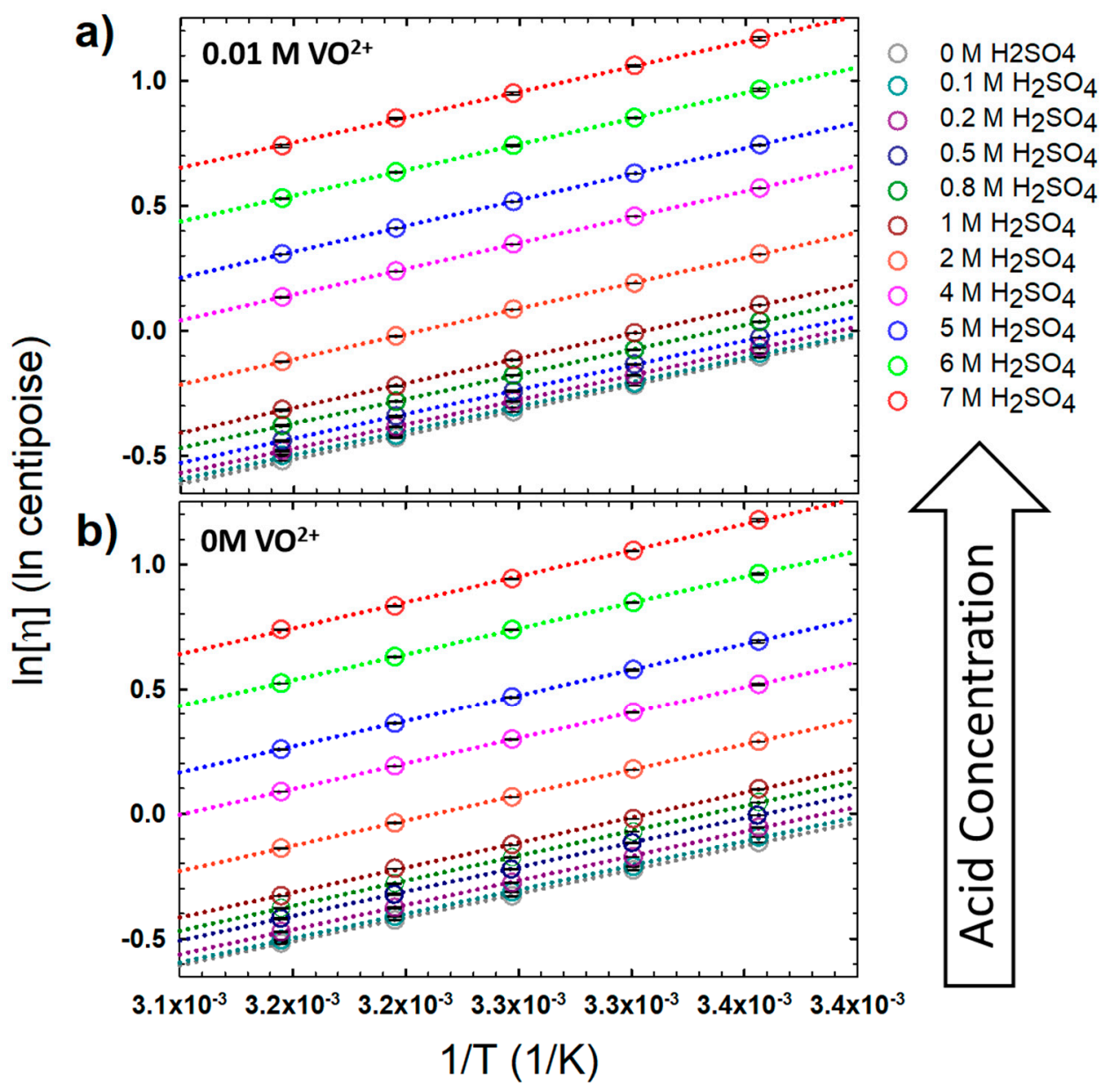

Figure 1. Arrhenius-type plots for viscous flow for (a) solutions with $0.01 \mathrm{M} \mathrm{VO}^{2+}$ and (b) blank $\mathrm{H}_{2} \mathrm{SO}_{4}$ solutions measured at 25, 30, 35, 40, and $45^{\circ} \mathrm{C}$. Data values in Figure 1 are also shown in Table A3.

Figure 2a,b shows sample EPR spectra of the $\mathrm{VO}^{2+}$ ion in $0.1 \mathrm{M}$ and $7 \mathrm{M} \mathrm{H}_{2} \mathrm{SO}_{4}$ at $25{ }^{\circ} \mathrm{C}$ and $-180{ }^{\circ} \mathrm{C}$, respectively. In Figure $2 \mathrm{~b}$, the lower $\mathrm{H}_{2} \mathrm{SO}_{4}$ concentration spectra show broadening due to unresolved hyperfine interactions, most likely a result of solute aggregation in the frozen 
solutions. Broadening in frozen solutions has been observed to dissipate with the addition of glycerin to the solution to deter nucleation, probably by slowing mobility with increased viscosity [26]. This broadening decreases with increasing $\mathrm{H}_{2} \mathrm{SO}_{4}$ concentration, which also increases the viscosity and lowers the $\mathrm{VO}^{2+}$ mobility (Figure $2 \mathrm{~b}$, inset). However, a steep drop in spectral broadening is observed with only small increases in $\mathrm{H}_{2} \mathrm{SO}_{4}$ concentration, where the viscosity does not significantly increase. For the lowest $\mathrm{H}_{2} \mathrm{SO}_{4}$ concentration measured, $0.1 \mathrm{M}$, the $\mathrm{pH}$ should be $<1$, and the $\mathrm{VO}^{2+}$ structure should be stable as an aquo-cation ligated by five water molecules [27]. The increased presence of additional ions in the solution must also play a role in deterring aggregation upon freezing, possibly by adding competition to ion redistribution observed in freezing liquids [28].

a)

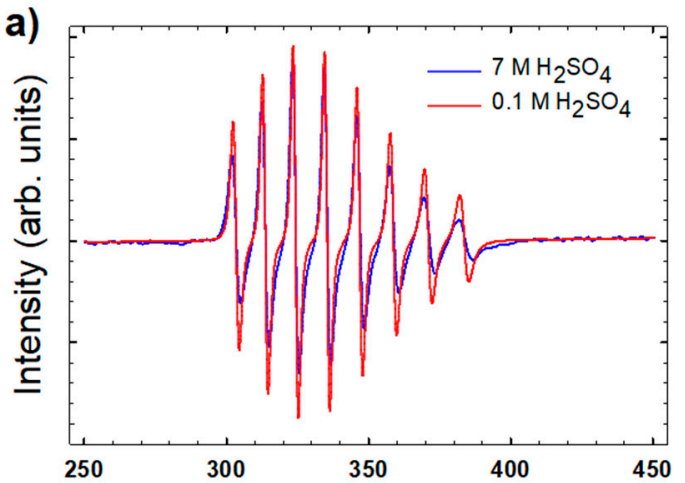

Field (mT)

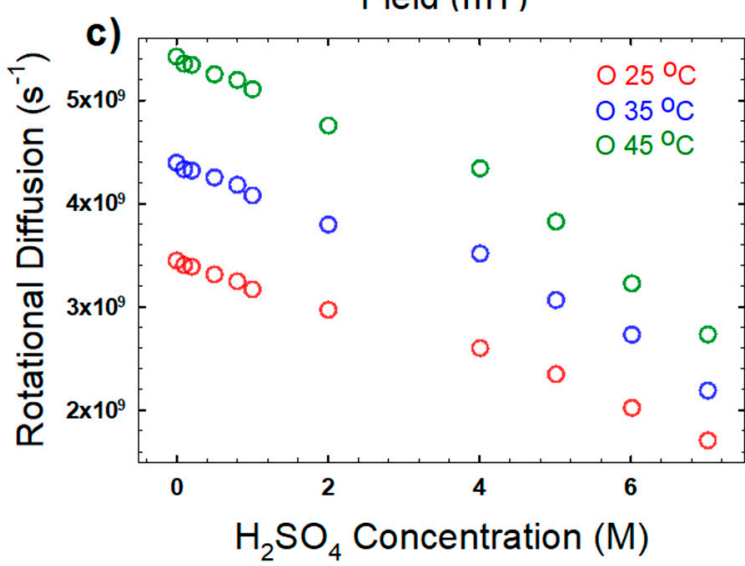

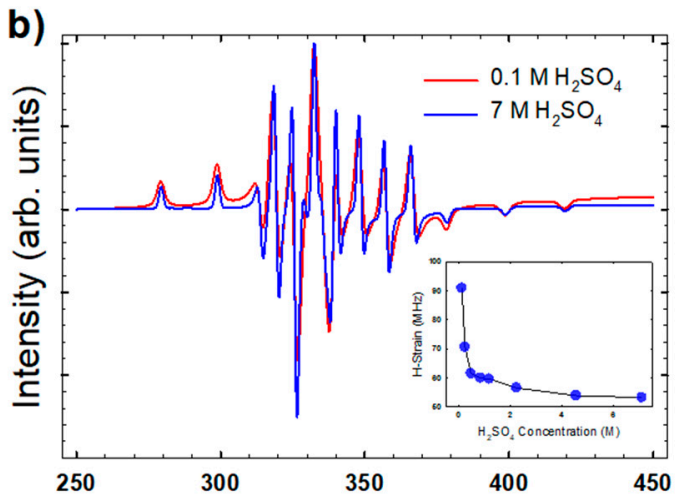

Field $(\mathrm{mT})$

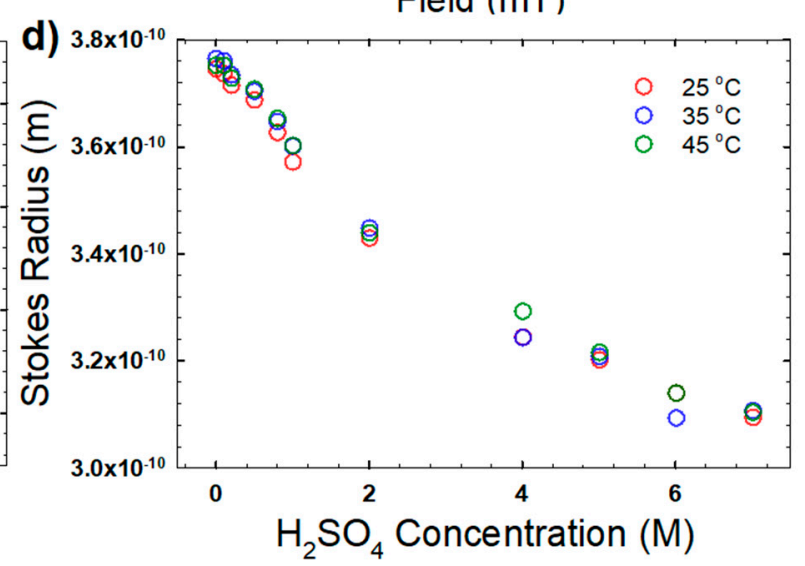

Figure 2. (a) Representative electron paramagnetic resonance (EPR) spectra at $25^{\circ} \mathrm{C}$ for the highest and lowest $\mathrm{H}_{2} \mathrm{SO}_{4}$ concentrations investigated; (b) EPR spectra collected at $-180{ }^{\circ} \mathrm{C}$ (inset shows unrefined hyperfine coupling); (c) extracted rotational diffusion coefficients using Equation (2); and (d) the Stokes radius of the vanadyl ion using Equation (2). EPR fitting parameters were $A_{\|}=542.6 \mathrm{MHz}$; $A_{\perp}=203.3 \mathrm{MHz} ; g_{\|}=1.943 ;$ and $g_{\perp}=1.989$.

The initial parameters for fitting the higher temperature spectra were determined by fits to the frozen spectra at $-180^{\circ} \mathrm{C}$. The value of $A_{\|}$, determined from the rigid limit spectra, is consistent with values reported in the literature [29], and is as expected for a complex with four equatorial water ligands [30]. EPR fitting parameters that were unaffected by the $\mathrm{H}_{2} \mathrm{SO}_{4}$ concentration are listed in the Figure 2 caption. The fitting parameter most affected by the $\mathrm{H}_{2} \mathrm{SO}_{4}$ concentration was the rotational diffusion, which decreased as $\mathrm{H}_{2} \mathrm{SO}_{4}$ concentration and viscosity increased (Figure 2c).

The stokes radius of the $\mathrm{VO}\left(\mathrm{H}_{2} \mathrm{O}\right)_{5}{ }^{2+}$ complex is related to the rotational diffusion through the Stokes-Einstein-Debye (SED) equation:

$$
D_{R}=\frac{k_{B} T}{8 \pi \eta r^{3}}
$$


Figure $2 \mathrm{~d}$ shows the results of this calculation. The radius decreases from $3.7 \mathrm{~A}$ to $3.1 \AA$ with increasing $\mathrm{H}_{2} \mathrm{SO}_{4}$ concentration. These values are in good agreement with values reported elsewhere [29,31,32]. The trend with $\mathrm{H}_{2} \mathrm{SO}_{4}$ concentration, however, is different than what was observed by Oriji et al. [23] in solutions with significantly higher $\mathrm{VO}^{2+}$ concentration $(\sim 2 \mathrm{M})$, where considerably lower Stokes radii $(2 \AA)$ were reported. The decreasing trend in the Stokes radius observed here is likely due to the higher $\mathrm{H}_{2} \mathrm{SO}_{4}$ concentrations disrupting the outermost hydration layer, possibly to hydrate the $\mathrm{H}_{2} \mathrm{SO}_{4}$.

The rotational diffusion and Stokes radius can be related to the translational diffusion through the Stokes-Einstein (SE) equation relating translational diffusion and viscosity:

$$
D_{T}=\frac{k_{B} T}{6 \pi \eta r}
$$

In addition, by combining Equations (2) and (3):

$$
\frac{D_{T}}{D_{R}}=\frac{4}{3} r^{2}
$$

The translational diffusion of $\mathrm{VO}^{2+}$ in the $\mathrm{H}_{2} \mathrm{SO}_{4}$ solutions as determined by EPR is shown in Figure 3, and will be discussed in greater detail in comparison to results obtained via electrochemistry below.

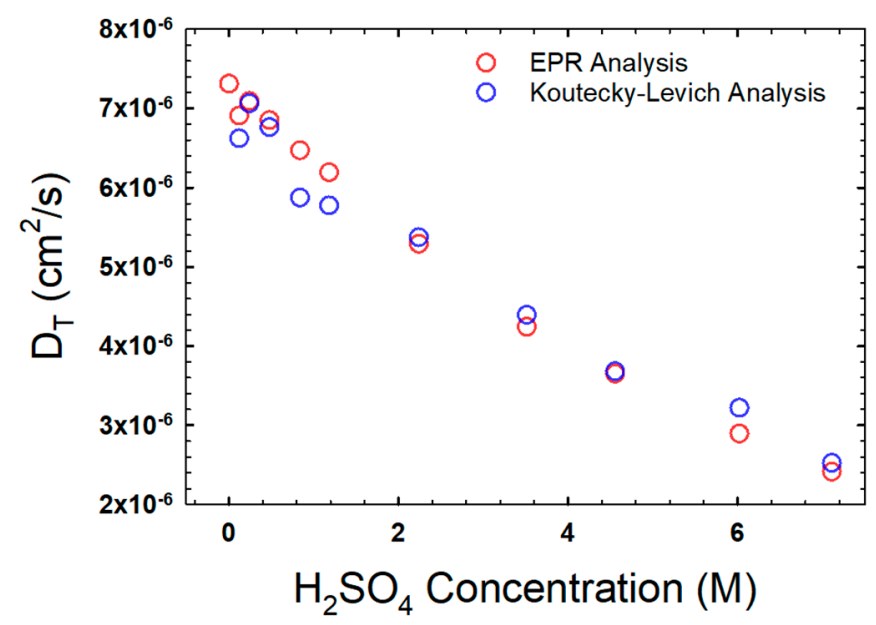

Figure 3. Translational diffusion coefficients as a function of $\mathrm{H}_{2} \mathrm{SO}_{4}$ concentration, as obtained via EPR (red circles) and rotating disc electrode analyses (blue circles). Both datasets are measured at $25^{\circ} \mathrm{C}$.

The oxidation of the $\mathrm{VO}^{2+}$ ion to $\mathrm{VO}_{2}{ }^{+}$proceeds via the following reaction:

$$
\mathrm{VO}\left(\mathrm{H}_{2} \mathrm{O}\right)_{5}{ }^{2+} \rightleftharpoons \mathrm{VO}_{2}\left(\mathrm{H}_{2} \mathrm{O}\right)_{4}^{+}+2 \mathrm{H}^{+}+\mathrm{e}^{-}
$$

At a $\mathrm{pH}<1$ and low vanadium concentration, the $\mathrm{V}(\mathrm{V})$ is expected to exist as a $\mathrm{VO}_{2}{ }^{+}$ion with a bent geometry, though there is some discussion as to whether it is more likely to be ligated by four or three water molecules [33].

Linear sweep voltammetry at a rotating disc electrode was analyzed by plotting the inverse of the square root of the rotation rate versus $1 / i$ in Figure 4 . The linear results fit with the Koutecky-Levich (K-L) equation:

$$
\frac{1}{i}=\frac{1}{i_{K}}+\frac{1}{0.62 n F A D_{T, 0}^{2 / 3} \omega^{1 / 2} \eta^{-1 / 6} C_{o}}
$$




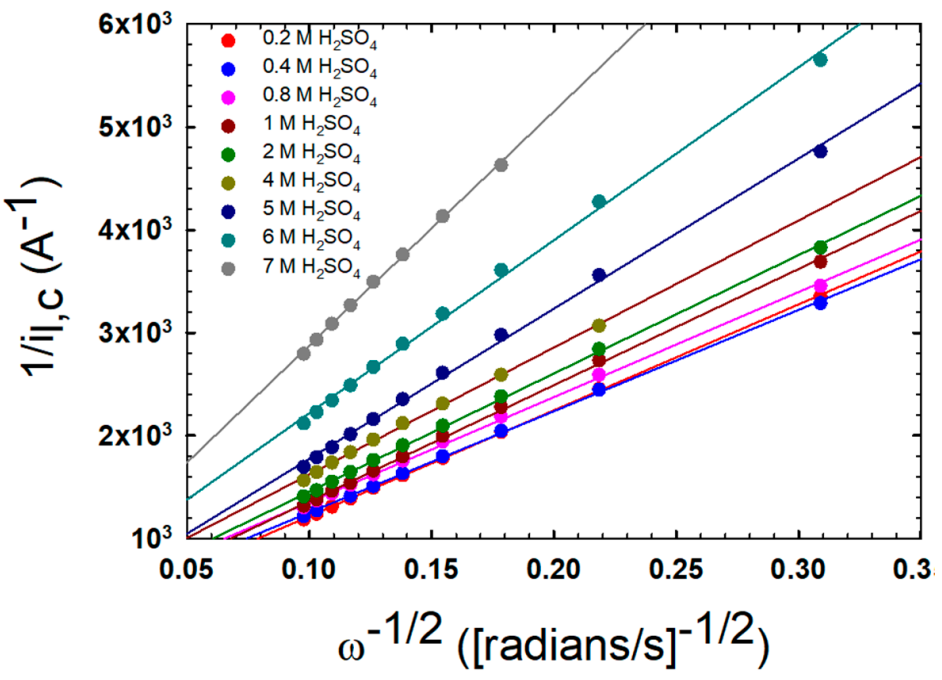

Figure 4. Results of the Koutecky-Levich $(\mathrm{K}-\mathrm{L})$ analysis of linear sweep voltammetry data measured for $0.01 \mathrm{M} \mathrm{VO}^{2+}$ in the indicated $\mathrm{H}_{2} \mathrm{SO}_{4}$ solutions at $25^{\circ} \mathrm{C}$.

Using this method, the translational diffusion, $D_{T}$, can be calculated from the slope of the line. The results from this method are compared to the results from the EPR in Figure 3, and they correlate well.

Figure 5 shows sample cyclic voltammograms for $\mathrm{VOSO}_{4} / \mathrm{H}_{2} \mathrm{SO}_{4}$ solutions. Figure 5 a shows the $\mathrm{CVs}$ as a function of the scan rate for the $7 \mathrm{M} \mathrm{H}_{2} \mathrm{SO}_{4}$ solution, while Figure $5 \mathrm{~b}$ plots the peak separation $\left(\Delta E_{p}\right)$ for the same. These data reveal that even for this highest acid concentration, the redox process is quasi-reversible at best, as fully reversible redox couples would exhibit $\Delta E_{p} \sim 59 \mathrm{mV}$. Here we observe a minimal peak separation of $86 \mathrm{mV}$ when the scan rate is $1 \mathrm{mV} / \mathrm{s}$. Additionally, the values of $\Delta E_{p}$ increase with the scan rate, which suggests that the reaction kinetics become in competition with mass transport for the faster scan rates, where the diffusion layer is thinner than for the slower rates [20]. Figure $5 \mathrm{c}$ shows the cyclic voltammogram $(\mathrm{CV})$ as a function of $\mathrm{H}_{2} \mathrm{SO}_{4}$ concentration at a fixed scan rate of $15 \mathrm{mV} / \mathrm{s}$. These CVs are qualitatively similar to those reported elsewhere [22]. Between 1-1.2 V vs. $\mathrm{Ag} / \mathrm{AgCl}$, the anodic part of the scan shows a peak associated with the oxidation of $\mathrm{V}(\mathrm{IV})$ to $\mathrm{V}(\mathrm{V})$. Ranging from $0.2-1 \mathrm{~V}$ of the cathodic part of the scan, there is a peak associated with the subsequent reduction of $\mathrm{V}(\mathrm{V})$ back to $\mathrm{V}(\mathrm{IV})$. This peak drifts to lower potentials with lower $\mathrm{H}_{2} \mathrm{SO}_{4}$ concentrations, and is more dependent on $\mathrm{H}_{2} \mathrm{SO}_{4}$ concentration than the anodic peak. Overall, as $\mathrm{H}_{2} \mathrm{SO}_{4}$ concentration decreases, the shape of the $\mathrm{CV}$ becomes more stretched out as $\Delta E_{p}$ increases and the peak currents decrease, which is characteristic of a shift from quasi-reversible to irreversible.
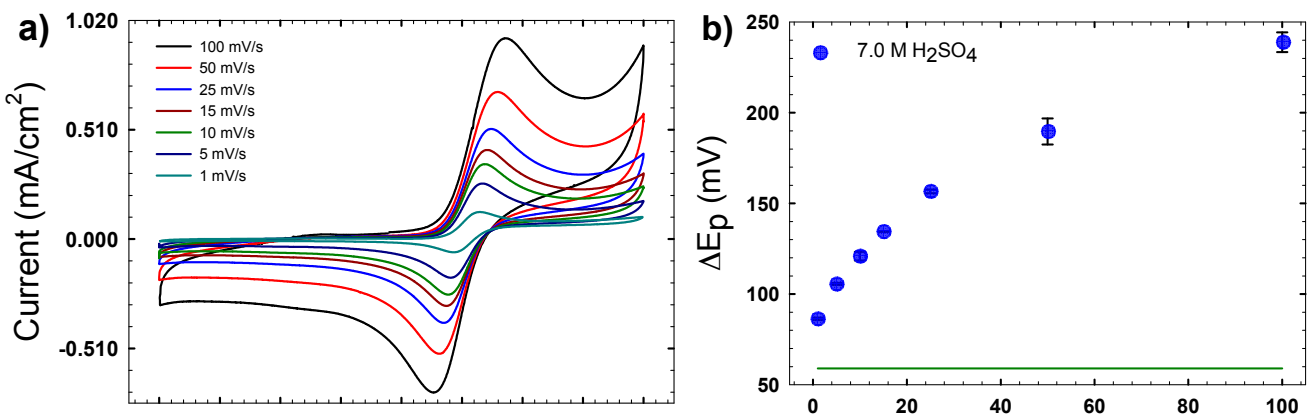

Figure 5. Cont. 

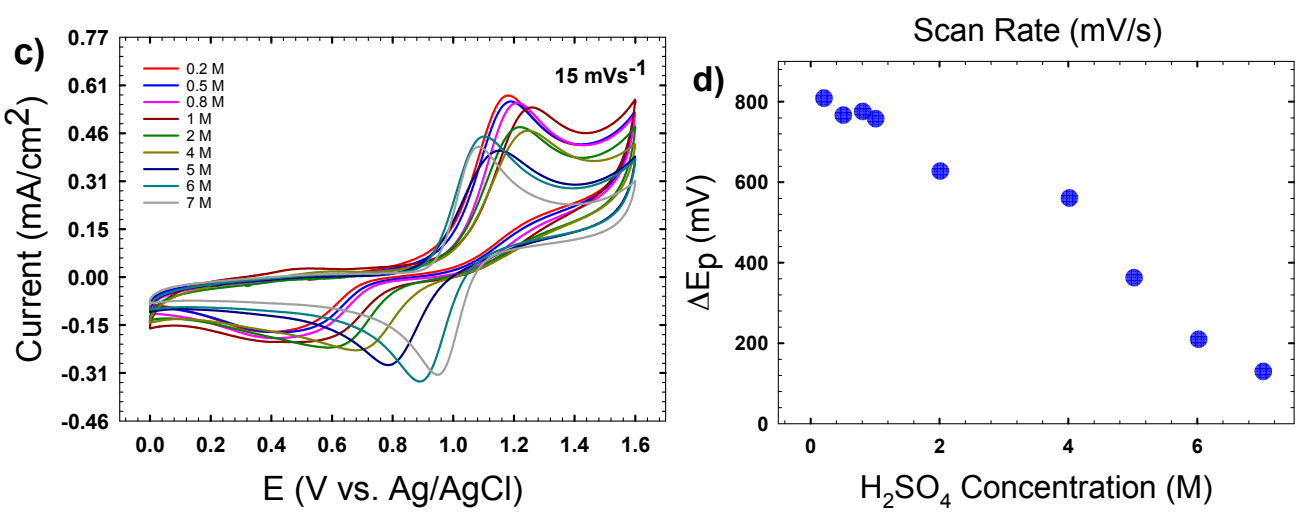

Figure 5. (a) Cyclic voltammograms (CVs) of $0.01 \mathrm{M} \mathrm{VO}^{2+}$ in $7 \mathrm{M} \mathrm{H}_{2} \mathrm{SO}_{4}$ at the indicated scan rates measured at $25^{\circ} \mathrm{C}$; (b) plot of peak separation $\left(\Delta E_{p}\right)$ from the $\mathrm{CVs}$ in (a); (c) a representative set of $\mathrm{CVs}$ of $0.01 \mathrm{M} \mathrm{VO}^{2+}$ as a function of $\mathrm{H}_{2} \mathrm{SO}_{4}$ concentration at $25^{\circ} \mathrm{C}$, with a scan rate of $15 \mathrm{mV} / \mathrm{s}$; (d) average $\Delta E_{p}$ for CVs measured at varying $\mathrm{H}_{2} \mathrm{SO}_{4}$ concentrations.

Further analyses of the CVs reveal interesting kinetic information on the oxidation of $\mathrm{VO}^{2+}$. The shape of the CVs, particularly at lower $\mathrm{H}_{2} \mathrm{SO}_{4}$ concentrations where $i_{p, a}>i_{p, c}$, suggests an EC (electrochemical [first reaction]/chemical [second reaction]) mechanism:

$$
\left[\mathrm{VO}\left(\mathrm{H}_{2} \mathrm{O}\right)_{5}\right]^{2+} \leftrightarrows\left[\mathrm{VO}\left(\mathrm{H}_{2} \mathrm{O}\right)_{5}\right]^{3+}+\mathrm{e}^{-} \leftrightarrows\left[\mathrm{VO}_{2}\left(\mathrm{H}_{2} \mathrm{O}\right)_{4}\right]^{+}+2 \mathrm{H}^{+}
$$

which is consistent with the EC mechanism proposed by Gattrell et al. [34]. The effect of the chemical step on the shape of the CV is then expected to truncate the cathodic peak and should be more pronounced in conditions where: (a) the chemical step has more time to occur before the cathodic scan begins (i.e., lower scan rate) and (b) the chemical reaction is able to occur very quickly before the cathodic scan begins (i.e., faster rate of the chemical step). The effect of scan rate can be probed qualitatively by observing the ratio of the peak heights $\left(i_{p, c} / i_{p, a}\right)$, In Figure 6a the calculated results are shown using the approximation by Nicholson [35]:

$$
\frac{i_{p, c}}{i_{p, a}}=\frac{\left(i_{p, c}\right)_{o}}{i_{p, a}}+\frac{0.485\left(i_{s p}\right)}{i_{p, a}}+0.086
$$

where $\left(i_{p, c}\right)_{o}$ is the position of the cathodic peak and $i_{s p}$ is the current at the switching potential, which here is taken as the minima between the anodic peak associated with the $\mathrm{VO}^{2+}$ oxidation and the switching potential. As the scan rates increase, the peak height ratio approaches 1 . At higher $\mathrm{H}_{2} \mathrm{SO}_{4}$ concentrations, the peak ratios also approach 1 , suggesting that the presence of $\mathrm{H}^{+}$in the solution (a product of the chemical step of the mechanism) alters the rate of the chemical step. Modeling works [36] have shown that an EC mechanism mostly effects the cathodic peak, leaving the anodic peak available for traditional analysis.

It can be observed from Figure 5 that as the CVs deviate from reversibility the peak heights decrease. The Randles-Sevcik equation for irreversible redox reactions accounts for this by adding the $\alpha n^{\prime}$ term:

$$
\begin{gathered}
i_{p}^{r e v}= \pm 0.446 n F A C\left(\frac{n F D v}{R T}\right)^{1 / 2} \\
i_{p}^{i r r e v}= \pm 0.496\left(\alpha n^{\prime}\right)^{\frac{1}{2}} n F A C\left(\frac{F D v}{R T}\right)^{1 / 2}
\end{gathered}
$$

where $n^{\prime}$ is the number of electrons transferred before the rate determining step. The relationship of $i_{p, a}$ with the square root of scan rate is shown in Figure $6 \mathrm{~b}$. If $\alpha=0.5$, the peak of the irreversible process is expected to be $80 \%$ of a theoretical reversible process with identical parameters [37]. 
Figure $6 \mathrm{c}$ demonstrates the use of the Randles-Sevcik equation for a reversible process to calculate the diffusion coefficient $\left(D_{T}\right)$ based on the actual anodic peak currents and anodic peak currents with an added $20 \%$ of height. Only the lowest scan rates were used to determine $D_{T}$ using this method. Low scan rates have been shown to deviate the least from peak values predicted by the Randles-Sevcik equation, in the case where pure Butler-Volmer kinetics are not predicted [38], which is suggested in publications reporting Tafel slopes for this system [34,39]. The average $\mathrm{D}_{\mathrm{T}}$ values determined from EPR and rotating disc electrodes (RDE) are plotted for comparison. At higher $\mathrm{H}_{2} \mathrm{SO}_{4}$ concentrations, the results calculating the diffusion from uncorrected peak heights compare well with those measured by other means, but the diffusion for lower $\mathrm{H}_{2} \mathrm{SO}_{4}$ concentrations trends low. The results of the calculation of the $\mathrm{D}_{\mathrm{T}}$ using the corrected peak currents, also plotted in Figure $6 \mathrm{c}$, show that lower $\mathrm{H}_{2} \mathrm{SO}_{4}$ concentrations compare well with the other methods, but also that higher $\mathrm{H}_{2} \mathrm{SO}_{4}$ concentrations trend high. This suggests that as the $\mathrm{H}_{2} \mathrm{SO}_{4}$ concentration decreases, and the redox processes deviate from reversibility, the $80 \%$ relationship becomes viable with an $\alpha$ value of 0.5 . Assuming an $\alpha$ value of 0.5 and diffusion coefficients determined by EPR and RDE, the potential peak separation, $\Delta E_{p}$, can be used to determine the standard heterogenous rate constant, $k_{0}$, using the relationship of Klingler and Kochi [22,40]:

$$
k_{o}=2.18\left[\frac{D \alpha v n F}{R T}\right]^{1 / 2} \exp \left[-\left(\frac{\alpha^{2} n F}{R T}\right)\left(E_{p}^{o x}-E_{p}^{r e d}\right)\right]
$$

This method is similar to the commonly used method of Nicholson and Shane [41], but is more appropriate for the larger values of $\Delta E_{p}$ (and therefore lower values of $k_{0}$ ), which are observed here for the lower $\mathrm{H}_{2} \mathrm{SO}_{4}$ concentrations. As Figure 6d illustrates, the rate of the electrochemical step on glassy carbon increases dramatically as $\mathrm{H}_{2} \mathrm{SO}_{4}$ concentration is increased (e.g., 72 times larger at $7 \mathrm{M}$ versus $0.1 \mathrm{M} \mathrm{H}_{2} \mathrm{SO}_{4}$ ).
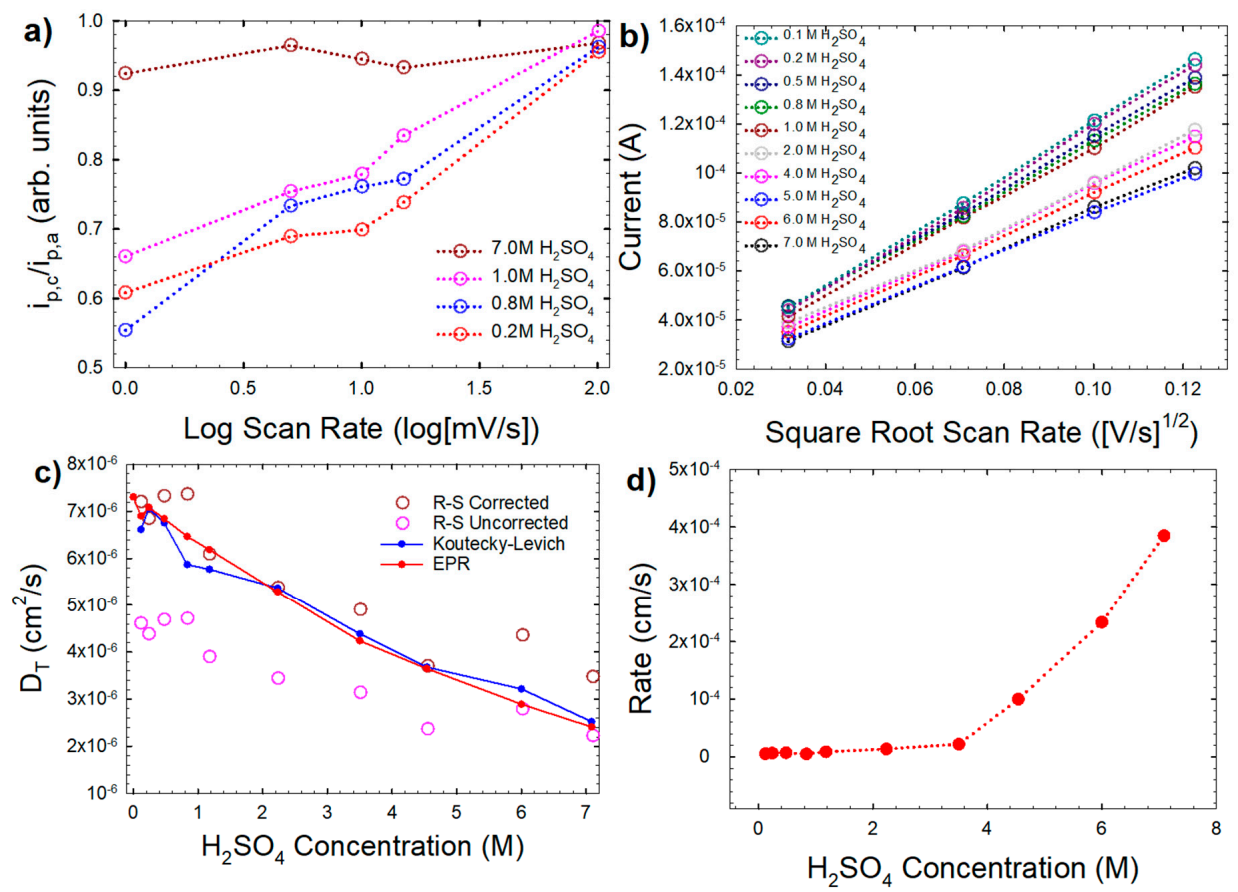

Figure 6. (a) Peak current ratios for the $\mathrm{CVs}$ of $0.01 \mathrm{M} \mathrm{VO}^{2+}$ in the indicated $\mathrm{H}_{2} \mathrm{SO}_{4}$ solutions as a function of scan rate (shown here as log of scan rate for clarity); (b) Randles-Sevcik (R-S) analysis of the CVs (four slowest scan rates) using Equation (8); (c) translational diffusion coefficient $\left(D_{T}\right)$ calculated from R-S analysis for corrected (red circles) and uncorrected (dark red hollow circles) peak currents in comparison to values obtained via $\mathrm{K}-\mathrm{L}$ and EPR analyses (the latter from Figure 3). The peak current correction applied was $+20 \%$ added to the anodic peak. (d) Heterogeneous rate constant $\left(k_{0}\right)$ at varying $\mathrm{H}_{2} \mathrm{SO}_{4}$ concentrations, as calculated using Equation (10). 


\section{Materials and Methods}

\subsection{Preparation of Electrolyte Solutions}

Electrolyte solutions were made to consist of $0.01 \mathrm{M} \mathrm{VOSO}_{4} \cdot \mathrm{xH}_{2} \mathrm{O}(\mathrm{x}=4.2$ via the certificate of analysis; Alfa Aesar, Ward Hill, MA, USA) and sulfuric acid (Sigma Aldrich, Burlington, MA, USA) at approximate target concentrations of $0 \mathrm{M}, 0.1 \mathrm{M}, 0.2 \mathrm{M}, 0.5 \mathrm{M}, 0.8 \mathrm{M}, 1.0 \mathrm{M}, 2.0 \mathrm{M}, 4.0 \mathrm{M}, 5.0 \mathrm{M}, 6.0 \mathrm{M}$, and 7.0 M. All acid stock solution concentrations were verified via titration with standardized $\mathrm{NaOH}$ prior to the addition of $\mathrm{VOSO}_{4}$. The actual titrated concentrations of $\mathrm{H}_{2} \mathrm{SO}_{4}$ were as follows: $0.1180 \mathrm{M}$, 0.2390 M, 0.4761 M, 0.8334 M, 1.176 M, 2.231 M, 3.502 M, 4.539 M, 6.012 M, and 7.086 M.

\subsection{Viscosity Measurements}

Measurements of dynamic viscosity were performed on each $\mathrm{H}_{2} \mathrm{SO}_{4}$ stock solutions, as well as the $\mathrm{VOSO}_{4}$ electrolyte solutions using a Cannon-Fenske routine viscometer (Fungilab, sizes 25, 50, 75, and 100, Hauppauge, NY, USA). Cleaned (piranha solution) and dried viscometers were filled with approximately $7 \mathrm{~mL}$ of solution and immersed in a thermostatic water bath (PolyScience, Niles, IL, USA) equipped with digital temperature control. Viscosity measurements were collected for each $\mathrm{H}_{2} \mathrm{SO}_{4}$ stock and electrolyte solutions at $25^{\circ} \mathrm{C}, 30^{\circ} \mathrm{C}, 35^{\circ} \mathrm{C}, 40{ }^{\circ} \mathrm{C}$, and $45^{\circ} \mathrm{C}$. To obtain the dynamic viscosity from the kinematic viscosity, the kinematic viscosity was divided by the density, $\rho$, for each solution, which was measured using calibrated micropipettes and an analytical balance accurate to five decimal places (Mettler Toledo XS105, Columbus, OH, USA).

Viscosity was calculated using the following relationship:

$$
\eta_{s}=\frac{\rho_{s}}{\rho_{w}} \frac{t_{s}}{t_{w}} \eta_{w}
$$

where the subscript $s$ refers to the solution investigated and subscript $w$ refers to water, while $\eta$ is viscosity $(\mathrm{cP}), \rho$ is density $\left(\mathrm{g} / \mathrm{cm}^{3}\right)$, and $t$ is time (s). Values for $\eta_{w}$ were adopted from known sources [42]. Errors were propagated using standard methods for error analysis in multi-measurement systems [43].

\subsection{Electron Paramagnetic Resonance (EPR) Measurements}

The $\mathrm{H}_{2} \mathrm{SO}_{4}$ and $\mathrm{VOSO}_{4}$ solutions were deoxygenated by bubbling with hydrated nitrogen for $1 \mathrm{~h}$. Samples were sealed in a capillary. Measurements were collected on an x-band EPR (Magnettech 5000 miniscope, Berlin, Germany) at $25-45^{\circ} \mathrm{C}$ and at $-180^{\circ} \mathrm{C}$. The spectra were fitted using Easyspin $[44,45]$.

\subsection{Electrochemical Measurements}

All electrochemical measurements were carried out in a $50 \mathrm{~mL}$ glass jacketed beaker electrochemical cell maintained at $25{ }^{\circ} \mathrm{C}$ and fitted with a machined Teflon lid. The working electrode was a glassy carbon rotating disc electrode (Pine Instruments, Grove City, PA, USA) with a $5.0 \mathrm{~mm}$ diameter attached to a Pine Instruments model MSR rotator. A Pt mesh spot welded to Pt wire was employed as the counter electrode, and the reference electrode was an $\mathrm{Ag} / \mathrm{AgCl}$ (saturated $\mathrm{NaCl}$, BASi, West Lafayette, IN, USA) reference electrode. All characterization was carried out using a Bio Logic SP-300 potentiostat equipped with two channel boards. Electrode pre-treatment included polishing with $1 \mu \mathrm{m}$ and $0.05 \mu \mathrm{m}$ alumina slurry (Electron Microscopy Sciences, Hatfield PA, USA) and sonicating in MilliQ 18.2 M $\cdot \mathrm{cm}$ deionized water (Millipore Sigma, Burlington MA, USA) for $5 \mathrm{~min}$.

\subsubsection{Rotating Disc Electrode (RDE) Experiments}

All RDE experiments were conducted on a Pine Instruments MSR rotator at rotation rates of 100, 200, 300, 400, 500, 600, 700, 800, 900, and 1000 RPMs sequentially. Five linear sweep voltammograms were collected for each rotation rate with potential limits of $0.1-1.6 \mathrm{~V}$ versus $\mathrm{Ag} / \mathrm{AgCl}$. In all cases, the 
electrolyte solutions were previously degassed by sparging with pre-hydrated Ar (ultra-high purity; Airgas, Radnor, PA, USA).

\subsubsection{Cyclic Voltammograms}

Cyclic voltammograms were collected for each of the $0.01 \mathrm{M} \mathrm{VOSO}_{4}$ electrolyte solutions using potential limits of $0.0-1.6 \mathrm{~V}$ versus $\mathrm{Ag} / \mathrm{AgCl}$ and scan rates of $100,50,25,15,10,5$, and $1 \mathrm{mVs}^{-1}$ for all $\mathrm{H}_{2} \mathrm{SO}_{4}$ concentrations.

\section{Conclusions}

In this initial investigation into the relationship between the $\mathrm{VO}^{2+}$ ion and $\mathrm{H}_{2} \mathrm{SO}_{4}$ concentration in bulk solution, diffusion of the $\mathrm{VO}^{2+}$ ion has been measured with similar results by different methods, and is in agreement with published reports. Of the three methods investigated, results from EPR and Koutecky-Levich were very consistent. The Stokes radius of $\mathrm{VO}^{2+}$ was observed to decrease with increasing acid concentration, likely as a result of the disruption of the second hydration layer by the higher $\mathrm{H}_{2} \mathrm{SO}_{4}$ concentrations. Qualitative mechanistic and rate information was observed from the electrochemistry of the solutions. These data suggest that the oxidation of $\mathrm{VO}^{2+}$ to $\mathrm{VO}_{2}{ }^{+}$proceeds by an EC mechanism, with the electrochemical step being faster with higher acid concentrations at the expense of the rate of the chemical step, as $\mathrm{H}^{+}$is a reaction product. Analysis of the cyclic voltammetry revealed that the redox process was electrochemically irreversible at $\mathrm{H}_{2} \mathrm{SO}_{4}$ concentrations of $<5 \mathrm{M}$, and quasi-reversible from 5-7 M, but approaching reversible with $\Delta E_{p}=75 \mathrm{mV}$ at $1 \mathrm{mV} / \mathrm{s}$ and $7 \mathrm{M}$ $\mathrm{H}_{2} \mathrm{SO}_{4}$. The methods developed here can be applied to the other VRFB-relevant reactions to gain a more detailed understanding of electrolyte solutions for redox flow batteries. This includes observations of more concentrated solutions and different electrode surfaces.

Author Contributions: J.S.L. and T.M.A. conceived the project and designed the experiments. S.M.T. collected all the electrochemistry data and a portion of the viscosity measurements and titrations. D.J.D. and S.P.F. measured the viscosity and performed the acid-base titrations. J.S.L. and T.M.A. collected the EPR data; J.S.L. analyzed and interpreted the EPR data. J.S.L. and T.M.A. analyzed the electrochemistry data and wrote the manuscript. All authors reviewed the manuscript.

Funding: This research was funded by in part by a Student Collaborative and Integrated Grant for Research (SCIG) from Salve Regina University, grant number [558112].

Acknowledgments: Sophia M. Tiano, Daniel J. Donnelly and Sean P. Flanagan acknowledge the NASA Rhode Island Space Grant Consortium (NASA) for summer undergraduate research scholarships (NNX15AI06H).

Conflicts of Interest: The authors declare no conflict of interest.

\section{Appendix A.}

Table A1. List of terms and symbols.

\begin{tabular}{cc}
\hline Term/Symbol & Definition \\
\hline$A_{\|}, A_{\perp}$ & Hyperfine splitting tensor, $\mathrm{MHz}$ \\
$\mathrm{A}$ & Electrode area, $\mathrm{cm}^{2}$ \\
$\mathrm{C}_{\mathrm{o}}$ & Concentration, $\mathrm{mol} \mathrm{m}^{-3}$ \\
$D_{R}$ & Rotational diffusion, $\mathrm{s}^{-1}$ \\
$D_{T}$ & Translational diffusion, $\mathrm{m}^{2} \mathrm{~s}^{-1}$ \\
$E_{p}^{o x}$ & Anodic peak potential, $\mathrm{V}$ \\
$E_{p}^{r e d}$ & Cathodic peak potential, $\mathrm{V}$ \\
$E_{a}$ & Activation energy, $\mathrm{kJ} \mathrm{mol}^{-1}$ \\
$F$ & Faraday's constant, $\mathrm{C} \mathrm{mol}^{-1}$ \\
$g_{\|}, g_{\perp}$ & g-tensor \\
$i$ & Current, Amperes \\
$i_{K}$ & Kinetic current, Amperes \\
\hline
\end{tabular}


Table A1. Cont.

\begin{tabular}{cc}
\hline Term/Symbol & Definition \\
\hline$i_{p, a}$ & Anodic peak current, Amperes \\
$i_{p, c}$ & Cathodic peak current, Amperes \\
$\left(i_{p, c}\right)_{0}$ & Cathodic peak current position, Amperes \\
$i_{s p}$ & Switching potential current, Amperes \\
$k_{B}$ & Boltzmann Constant, $\mathrm{m}^{2} \mathrm{~kg} \mathrm{~s}^{-2} \mathrm{~K}^{-1}$ \\
$k_{0}$ & Rate constant cm s${ }^{-1}$ \\
$n$ & Moles \\
$\eta$ & Viscosity, $\mathrm{cP}$ \\
$\eta_{\infty}$ & Arrhenius preexponential factor cP \\
$r$ & Hydrodynamic radius, $\mathrm{m}$ \\
$R$ & Gas constant, J mol ${ }^{-1} \mathrm{~K}-1$ \\
$T$ & Temperature, $\mathrm{K}$ \\
$\alpha$ & Electron transfer constant \\
$\Delta E_{p}$ & Difference in peak potentials, $\mathrm{V}$ \\
$v$ & Scan rate, $\mathrm{V} \mathrm{s}^{-1}$ \\
$\omega$ & Rotation rate, rad s ${ }^{-1}$ \\
\hline
\end{tabular}

Table A2. Dynamic viscosity of sulfuric acid/sulfuric acid $\mathrm{VO}^{2+}$ electrolytes at the indicated temperatures, in units of centipoise $(\mathrm{cP})$.

\begin{tabular}{cccccc}
\hline No VO'+ & \multicolumn{5}{c}{ Temperature (K) } \\
\hline Sulfuric Acid Conc. $\left(\mathrm{mol} \mathrm{L}^{-1}\right)$ & 298 & 303 & 308 & 313 & 318 \\
0 & 0.890 & 0.797 & 0.719 & 0.653 & 0.596 \\
0.1 & 0.909 & 0.809 & 0.730 & 0.663 & 0.603 \\
0.2 & 0.945 & 0.840 & 0.758 & 0.686 & 0.623 \\
0.5 & 0.993 & 0.890 & 0.801 & 0.724 & 0.658 \\
0.8 & 1.046 & 0.929 & 0.839 & 0.756 & 0.685 \\
1.0 & 1.102 & 0.979 & 0.882 & 0.802 & 0.719 \\
2.0 & 1.333 & 1.192 & 1.067 & 0.962 & 0.870 \\
4.0 & 1.679 & 1.499 & 1.344 & 1.208 & 1.090 \\
5.0 & 1.999 & 1.781 & 1.595 & 1.433 & 1.291 \\
6.0 & 2.613 & 2.330 & 2.089 & 1.875 & 1.685 \\
7.0 & 3.242 & 2.869 & 2.562 & 2.296 & 2.092 \\
\hline 0.01 mol L-1 VO $^{2+}$ & & & Temperature (K) & \\
\hline Sulfuric Acid Conc. (mol L & & & & \\
0 & 298 & 303 & 308 & 313 & 318 \\
0.1 & 0.901 & 0.804 & 0.723 & 0.652 & 0.595 \\
0.2 & 0.913 & 0.812 & 0.736 & 0.658 & 0.607 \\
0.5 & 0.935 & 0.836 & 0.754 & 0.681 & 0.619 \\
0.8 & 0.973 & 0.874 & 0.785 & 0.710 & 0.644 \\
1.0 & 1.037 & 0.927 & 0.836 & 0.753 & 0.684 \\
2.0 & 1.108 & 0.991 & 0.890 & 0.801 & 0.729 \\
4.0 & 1.358 & 1.209 & 1.089 & 0.979 & 0.884 \\
5.0 & 1.768 & 1.579 & 1.414 & 1.268 & 1.144 \\
6.0 & 2.103 & 1.875 & 1.675 & 1.507 & 1.359 \\
7.0 & 2.622 & 2.342 & 2.098 & 1.885 & 1.698 \\
& 3.215 & 2.887 & 2.583 & 2.339 & 2.095 \\
\hline
\end{tabular}


Table A3. Arrhenius parameters extracted from data in Figure 1.

\begin{tabular}{ccc}
\hline $\mathbf{H}_{\mathbf{2}} \mathbf{S O}_{\mathbf{4}}$ Concentration (M) No $\mathbf{V O}^{2+}$ & $\mathbf{E}_{\mathbf{a}}(\mathbf{k J} / \mathbf{m o l})$ & $\eta_{\infty}(\mathbf{c P})$ \\
\hline 0 & 16.41 & $1.19 \times 10^{-3}$ \\
0.1 & 16.19 & $1.32 \times 10^{-3}$ \\
0.2 & 16.25 & $1.32 \times 10^{-3}$ \\
0.5 & 16.27 & $1.37 \times 10^{-3}$ \\
0.8 & 16.37 & $1.40 \times 10^{-3}$ \\
1.0 & 16.56 & $1.39 \times 10^{-3}$ \\
2.0 & 16.88 & $1.42 \times 10^{-3}$ \\
4.0 & 17.18 & $1.72 \times 10^{-3}$ \\
5.0 & 17.22 & $2.02 \times 10^{-3}$ \\
6.0 & 17.12 & $2.62 \times 10^{-3}$ \\
7.0 & 16.81 & $3.63 \times 10^{-3}$ \\
\hline $\mathbf{H}_{\mathbf{2}} \mathbf{S O}_{\mathbf{4}}$ Concentration (M) With $\mathbf{0 . 0 1} \mathbf{M ~ V O}^{2+}$ & $\mathbf{E}_{\mathbf{a}} \mathbf{( k J / m o l )}$ & $\eta_{\infty}(\mathbf{c P})$ \\
\hline 0.1 & 16.08 & $1.37 \times 10^{-3}$ \\
0.2 & 16.32 & $1.30 \times 10^{-3}$ \\
0.5 & 16.23 & $1.42 \times 10^{-3}$ \\
0.8 & 16.58 & $1.29 \times 10^{-3}$ \\
1.0 & 16.58 & $1.36 \times 10^{-3}$ \\
2.0 & 16.84 & $1.49 \times 10^{-3}$ \\
4.0 & 17.01 & $1.75 \times 10^{-3}$ \\
5.0 & 17.17 & $1.96 \times 10^{-3}$ \\
6.0 & 17.24 & $2.49 \times 10^{-3}$ \\
7.0 & 17.33 & $2.97 \times 10^{-3}$ \\
\hline
\end{tabular}

\section{References}

1. Skyllas-Kazacas, M.; Rychcik, M.; Robins, R.G.; Fane, A.G.; Green, M.A. New All-Vanadium Redox Flow Cell. J. Electrochem. Soc. 1986, 133, 1057-1058. [CrossRef]

2. Elgammal, R.A.; Tang, Z.; Sun, C.-N.; Lawton, J.; Zawodzinski, T.A. Species Uptake and Mass Transport in Membranes for Vanadium Redox Flow Batteries. Electrochim. Acta 2017, 237, 1-11. [CrossRef]

3. Gandomi, Y.A.; Aaron, D.S.; Zawodzinski, T.A.; Mench, M.M. In Situ Potential Distribution Measurement and Validated Model for All-Vanadium Redox Flow Battery. J. Electrochem. Soc. 2016, 163, A5188-A5201. [CrossRef]

4. Lawton, J.S.; Jones, A.; Zawodzinski, T. Concentration dependence of $\mathrm{VO}^{2+}$ crossover of nafion for vanadium redox flow batteries. J. Electrochem. Soc. 2013, 160, A697-A702. [CrossRef]

5. Lawton, J.S.; Jones, A.M.; Tang, Z.; Lindsey, M.; Zawodzinski, T. Ion effects on vanadium transport in Nafion membranes for vanadium redox flow batteries. J. Electrochem. Soc. 2017, 164, A2987-A2991. [CrossRef]

6. Gandomi, Y.A.; Aaron, D.S.; Houser, J.R.; Daugherty, M.C.; Clement, J.T.; Pezeshki, A.M.; Ertugrul, T.Y.; Moseley, D.P.; Mench, M.M. Critical Review_Experimental Diagnostics and Material Characterization Techniques Used on Redox Flow Batteries. J. Electrochem. Soc. 2018, 165, A970-A1010. [CrossRef]

7. Knehr, K.W.; Kumbur, E.C. Open circuit voltage of vanadium redox flow batteries: Discrepancy between models and experiments. Electrochem. Commun. 2011, 13, 342-345. [CrossRef]

8. Lawton, J.S.; Jones, A.M.; Tang, Z.; Lindsey, M.; Fujimoto, C.; Zawodzinski, T.A. Characterization of Vanadium Ion Uptake in Sulfonated Diels Alder Poly(phenylene) Membranes. J. Electrochem. Soc. 2016, 163, A5229-A5235. [CrossRef]

9. Lawton, J.S.; Aaron, D.S.; Tang, Z.; Zawodzinski, T.A. Qualitative behavior of vanadium ions in Nafion membranes using electron spin resonance. J. Membr. Sci. 2013, 428, 38-45. [CrossRef]

10. Kim, S.; Yan, J.; Schwenzer, B.; Zhang, J.; Li, L.; Liu, J.; Yang, Z.; Hickner, M.A. Cycling performance and efficiency of sulfonated poly(sulfone) membranes in vanadium redox flow batteries. Electrochem. Commun. 2010, 12, 1650-1653. [CrossRef] 
11. Schwenzer, B.; Kim, S.; Vijayakumar, M.; Yang, Z.; Liu, J. Correlation of structural differences between Nafion/polyaniline and Nafion/polypyrrole composite membranes and observed transport properties. J. Membr. Sci. 2011, 372, 11-19. [CrossRef]

12. Liang, X.; Peng, S.; Lei, Y.; Gao, C.; Wang, N.; Liu, S.; Fang, D. Effect of L-glutamic acid on the positive electrolyte for all-vanadium redox flow battery. Electrochim. Acta 2013, 95, 80-86. [CrossRef]

13. Wu, X.; Liu, S.; Wang, N.; Peng, S.; He, Z. Influence of organic additives on electrochemical properties of the positive electrolyte for all vanadium redox flow battery. Electrochim. Acta 2012, 78, 475-482. [CrossRef]

14. Roe, S.; Menictas, C.; Skyllas-Kazacos, M. A High Energy Density Vanadium Redox Flow Battery with 3 M Vanadium Electrolyte. J. Electrochem. Soc. 2016, 163, A5023-A5028. [CrossRef]

15. Skyllas-Kazacos, M.; Cao, L.; Kazacos, M.; Kausar, N.; Mousa, A. Vanadium Electrolyte Studies for the Vanadium Redox Battery-A Review. ChemSusChem 2016, 9. [CrossRef] [PubMed]

16. Li, H.; Schlick, S. Effect of solvents on phase separation in perfluorinated ionomers, from electron spin resonance of $\mathrm{VO}^{2+}$ in swollen membranes, and solutions. Polymer 1995, 36, 1141-1146. [CrossRef]

17. Szajdzinska-pietek, E.; Pilar, J.; Schlick, S. Structure and Dynamics of Perfluorinated Ionomers in Aqueous Solutions and Swollen Membranes Based on Simulations of ESR Spectra From Spin Propes. J. Phys. Chem. 1995, 99, 313-319. [CrossRef]

18. Alonso-Amigo, M.G.; Schlick, S. Determination of the Distance between Paramagnetic Centers from Electron Spin Resonance Spectra at L, S, and X Bands. Copper(2+) in Nafion Ionomers. Macromolecules 1989, 22, 2628-2634. [CrossRef]

19. Lawton, J.S.; Smotkin, E.S.; Budil, D.E. Electron spin resonance investigation of microscopic viscosity, ordering, and polarity in nafion membranes containing methanol-water mixtures. J. Phys. Chem. B 2008, 112, 8549-8557. [CrossRef] [PubMed]

20. Lawton, J.S.; Budil, D.E. Electron spin resonance investigaion of the effects of methanol on microscopic viscosity, ordering, and polarity in different phases of ionomer membranes with sulfonated polyarylene backbones. J. Membr. Sci. 2010, 357, 47-53. [CrossRef]

21. Aristov, N.; Habekost, A. Cyclic Voltammetry-A Versatile Electrochemical Method Investigating Electron Transfer Processes. World J. Chem. Educ. 2015, 3, 115-119.

22. Brownson, D.A.C.; Banks, C.E. The Handbook of Graphene Electrochemistry, 1st ed.; Springer: London, UK, 2014.

23. Oriji, G.; Katayama, Y.; Miura, T. Investigation on V(IV)/V(V) species in a vanadium redox flow battery. Electrochim. Acta 2004, 49, 3091-3095. [CrossRef]

24. Aaron, D.; Sun, C.-N.; Bright, M.; Papandrew, A.B.; Mench, M.M.; Zawodzinski, T.A. In Situ Kinetics Studies in All-Vanadium Redox Flow Batteries. ECS Electrochem. Lett. 2013, 2, A29-A31. [CrossRef]

25. Bourke, A.; Miller, M.A.; Lynch, R.P.; Wainright, J.S.; Savinell, R.F.; Buckley, D.N. Electrode Kinetics in All-Vanadium Flow Batteries: Effects of Electrochemical Treatment. ECS Trans. 2015, 66, 181-211. [CrossRef]

26. Albanese, N.F.; Chasteen, N.D. Origin of the electron paramagnetic resonance line widths in frozen solution of the oxovanadium(IV) ion. J. Phys. Chem. 1978, 82, 910-914. [CrossRef]

27. Selbin, J. The Chemistry of Oxovanadium(IV). Chem. Rev. 1965, 65, 153-175. [CrossRef]

28. Shafique, U.; Anwar, J.; Ali Munawar, M.; Zaman, W.U.; Rehman, R.; Dar, A.; Salman, M.; Saleem, M.; Shahid, N.; Akram, M.; et al. Chemistry of ice: Migration of ions and gases by directional freezing of water. Arab. J. Chem. 2016, 9, S47-S53. [CrossRef]

29. Barklie, R.C.; Girard, O.; Braddell, O. EPR of vanadyl (2+) in a Nafion membrane. J. Phys. Chem. 1988, 92, 1371-1377. [CrossRef]

30. Smith, T.S.; LoBrutto, R.; Pecoraro, V.L. Paramagnetic spectroscopy of vanadyl complexes and its applications to biological systems. Coord. Chem. Rev. 2002, 228, 1-18. [CrossRef]

31. Reuben, J.; Fiat, D. Proton and Deuteron Relaxation in Aqueous Solutions of Vanadyl(IV). Effects of Electron Spin Relaxation and Chemical Exchange. J. Am. Chem. Soc. 1969, 1611, 4652-4656. [CrossRef]

32. Chasteen, D.; Hanna, M. Resonance Line Widths of vanadyl(IV) hydroxycarboxylates. J. Phys. Chem. 1972, 76, 3951-3959. [CrossRef]

33. Vijayakumar, M.; Li, L.; Graff, G.; Liu, J.; Zhang, H.; Yang, Z.; Zhi, J. Towards understanding the poor thermal stability of V5+ electrolyte solution in Vanadium Redox Flow Batteries. J. Power Sources 2011, 196, 3669-3672. [CrossRef]

34. Gattrell, M.; Park, J.; MacDougall, B.; Apte, J.; McCarthy, S.; Wu, C.W. Study of the Mechanism of the Vanadium 4+/5+ Redox Reaction in Acidic Solutions. J. Electrochem. Soc. 2004, 151, A123-A130. [CrossRef] 
35. Nicholson, R.S. Theory and Application of Cyclic Voltammetry for Measurement of Electrode Reaction Kinetics. Anal. Chem. 1965, 37, 1351-1355. [CrossRef]

36. Elgrishi, N.; Rountree, K.J.; McCarthy, B.D.; Rountree, E.S.; Eisenhart, T.T.; Dempsey, J.L. A Practical Beginner's Guide to Cyclic Voltammetry. J. Chem. Educ. 2018, 95, 197-206. [CrossRef]

37. Batchelor-Mcauley, C.; Kätelhön, E.; Barnes, E.O.; Compton, R.G.; Laborda, E.; Molina, A. Recent Advances in Voltammetry. ChemistryOpen 2015, 4, 224-260. [CrossRef] [PubMed]

38. Henstridge, M.C.; Laborda, E.; Dickinson, E.J.F.; Compton, R.G. Redox systems obeying Marcus-Hush-Chidsey electrode kinetics do not obey the Randles-Ševčík equation for linear sweep voltammetry. J. Electroanal. Chem. 2012, 664, 73-79. [CrossRef]

39. Zhong, S.; Skyllas-Kazacos, M. Electrochemical behaviour of vanadium(V)/vanadium(IV) redox couple at graphite electrodes. J. Power Sources 1992, 39, 1-9. [CrossRef]

40. Klingler, R.J.; Kochi, J.K. Electron-transfer kinetics from cyclic voltammetry. Quantitative description of electrochemical reversibility. J. Phys. Chem. 1981, 85, 1731-1741. [CrossRef]

41. Nicholson, R.S.; Shain, I. Theory of Stationary Electrode Polarography: Single Scan and Cyclic Methods Applied to Reversible, Irreversible, and Kinetic Systems. Anal. Chem. 1964, 36, 706-723. [CrossRef]

42. Lide, D.R. CRC Handbook of Chemistry and Physics, 84th ed.; CRC Press LLC: New York, NY, USA, 2003.

43. Shoemaker, D.P.G.; Carl, W.; Nibler, J.W. Experiments in Physical Chemistry, 6th ed.; McGraw Hill: Boston, MA, USA, 1996.

44. Stoll, S.; Schweiger, A. EasySpin, a comprehensive software package for spectral simulation and analysis in EPR. J. Magn. Reson. 2006, 178, 42-55. [CrossRef] [PubMed]

45. Stoll, S.; Schweiger, A. EasySpin: Simulating cw ESR spectra. Biol. Magn. Reson. 2007, 27, $299-321$.

(C) 2018 by the authors. Licensee MDPI, Basel, Switzerland. This article is an open access article distributed under the terms and conditions of the Creative Commons Attribution (CC BY) license (http://creativecommons.org/licenses/by/4.0/). 